Volume, 13, n. 1, ano 2017

\title{
MASCULINIDADE E EDUCAÇÃO NO CAMPO Profissionalização e subjetividades docentes
}

\author{
Welson B. Santos ${ }^{1}$ \\ Thiago F. Sant'Anna ${ }^{2}$ \\ Higor Júnior $^{3}$
}

\begin{abstract}
RESUMO: Partimos do princípio de que discutir docência alinhavada ao conceito de masculinidades conduz-nos a uma articulação com o campo do debate de gênero e este texto não foge a tal debate. Mas, consideramos também que referir-se a docência requer entendimento desse fazer profissional e que requer saberes edificados e melhor sistematizados nos processos de formação das licenciaturas. Logo, quando levantamos questionamentos sobre as subjetividades que envolvem o masculino na sala de aula da escola do campo, consideramos que, embora considerado avanço se tenha alcançado para com o entendimento de que tal prática é aprendida culturalmente, persiste na escola e em dados espaços da sociedade o pressuposto de que a mulher executa o magistério melhor por ser mais apta para tal labor. Então, a partir de uma discussão sobre o masculino e os saberes docentes e, ainda, metodologicamente referenciados nos estudos de Michel Foucault e Robert W Connell foi estruturado a discussão aqui apresentada, como aporte realizamos entrevistas com professores masculinos que atuam em escolas do campo e buscamos entender as dinâmicas, objetivações e subjetivações que tais sujeitos enfrentam ao atuarem como professores da escola no nosso tempo.
\end{abstract}

Palavra-chave: Educação. Subjetividade. Masculinidade. Gênero

\section{MASCULINITY AND RURAL EDUCATION Professionalization and teacher subjectivities}

\begin{abstract}
We start from the idea that discussing teaching aligned with the concept of masculinity leads us to an articulation with the field of gender debate, and this paper does not escape such end. However, we also consider that referring to teaching requires an understanding of this professional doing and that it requires edified and better systematized knowledge of the processes of graduating as a teacher. Therefore, when we raise questions about the subjectivities that surround the masculine in a classroom of rural
\end{abstract}

\footnotetext{
${ }^{1}$ Graduado em Ciências Exatas e Naturais pela Universidade de Uberaba - UNIUBE, possui Doutorado em Educação pela Universidade Federal de São Carlos - UFSCar, na Área de Concentração Educação Cultura e Subjetividades; e Pós-Doutorando em Educação Sexual pelo Programa de Pós-Graduação em Educação sexual da Faculdade de Filosofia Ciências e Letras - UNESP. Atualmente, é professor Adjunto da Universidade Federal de Goiás/ Regional Cidade de Goiás. Email: wwsantosw@yahoo.com.br

${ }^{2}$ Graduado em História e em Serviço Social pela PUC-GO, possui Doutorado em História pela Universidade de Brasília, na Área de Concentração em Estudos Feministas e de Gênero; e Pós-Doutorado em Arte e Cultura Visual pelo Programa de Pós-Graduação em Artes e Cultura Visual, da Faculdade de Artes Visuais, da Universidade Federal de Goiás, onde atua como professor permanente. Atualmente, é professor do graduação Arquitetura e Urbanismo da Universidade Federal de Goiás/ Regional Cidade de Goiás. Email: thiagof.santanna@ yahoo.com.br

${ }^{3}$ Graduando de Licenciatura em Educação do Campo - LedoC, na Universidade Federal de Goiás/ Regional Cidade de Goiás. Aluno de iniciação científica e participante do projeto de pesquisa $O$ Gênero e a sexualidade na discussão: reconhecendo as diferenças para o melhor viver. e-mail: higor@gmail.com
} 


\section{ITTEERARUUS REFLECTIONIS}

Volume, 13, n. 1, ano 2017

schools, we consider that, although significant advance has been reached as to understanding that such practice is learnt culturally, it persists, in schools and given social spaces, the assumption that women execute the teaching better for being more apt to the job. Then, starting from a discussion about the masculine and the teaching knowledge, and also methodologically referred on Michael Foucault and Robert W. Connell's studies, the following considerations were presented. As a foundation, we used interviews with male teachers who act in rural schools and we sought to understand the dynamics, objectivations and subjectivations that such individuals face when working as teachers in our contemporary schools.

Key-words: Education. Subjectivity. Masculinity. Gender

\section{Introdução}

Este artigo é um recorte de um trabalho investigativo com professores e professoras de crianças e adolescentes campesinos na segunda fase do Ensino Fundamental de quatro escolas do campo no Município de Goiás - GO. Obtivemos consentimento para realização da pesquisa juntamente com a direção de cada uma dessas unidades escolares, dentro das quais coletamos dados de nove docentes, dos quais apenas uma era do sexo masculino, o qual ministrava a disciplina de Ciências da Natureza. Foi tal dado estatístico, acerca do sexo que nos conduziu a investigar questões sob a ótica do conceito de gênero na escola campesina e as subjetividades que as envolvem.

Assim, à nossa inspiração voltada para discutir a questão de gênero, somou-se o nosso interesse em abordar o descontínuo nesse corpus selecionado: Masculinidade e Educação do campo, as subjetividades docentes e sua profissionalização. Somos cientes de que a investigação da docência implica reconhecermos o que entendemos por educar. Nesse caminho, a identificamos como sendo prática que envolve habilidades, conhecimentos e subjetividades ${ }^{4}$, pilares estes que se estabelecem mesmo antes da profissionalização acadêmica e contínua que se

\footnotetext{
${ }^{4}$ Referente à subjetividade, trata-se de reforços nas constituições de sujeitos consequência de mecanismos de poder e de vontade de verdade que o atravessa cada um/a e acaba por dar a cada um a sua forma. Para Foucault (2011), seria a ética enquanto constituição de si, como sujeito para si mesmo e de seus próprios atos. Seria o que se sabe de si para si em uma procura das próprias verdades. Trata-se, portanto, do constitutivo de cada um/a.
} 


\section{ITTEEARUUS REFLECTIONIS}

Volume, 13, n. 1, ano 2017

segue à formação inicial. Portanto, a educação, aqui pensada enquanto prática, revelanos relações que carecem de ser menos hierarquizadas entre os saberes escolares e os saberes acadêmicos disponibilizados nos cursos de graduação.

Ainda, ao lado da prática do educar, alinhavamos outro conceito, a saber, o de sujeito, tomado aqui sob a ótica foucaultiana, de acordo com a qual, longe de ser uma entidade dada a priori, pronta e acabada, o sujeito, no caso o sujeito masculino, está o todo tempo em processo de construção, apresentando-se como um efeito, um construto que é laboriosamente fabricado enquanto uma posição de discurso e atravessado pelos mesmos a todo tempo. Trata-se de uma compreensão ancorada em

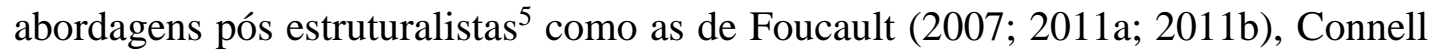
(1995; 2013) e Louro (1997), dentre outros. Ao lado destes, pretendemos dialogar com pensadores da educação e dos saberes docentes como Marice Tardif, Lee Shulman e Philippe Perrenold.

\section{Mapeando uma prática discursiva do educar}

Não seria um despropósito afirmar que a escola é um local em que funcionam espaços virtuais de comunicação, os quais são recursos úteis e eficientes para o cumprimento de inúmeras tarefas que abrangem múltiplos desafios metodológicos. Ainda, a escola é também um campo para experiências com diversas abordagens qualitativas centradas nas subjetividades de sujeitos do sexo masculino e atuantes na educação do campo no Município de Goiás - GO.

Por ser assim e sob a ótica de uma pesquisa qualitativa, vale ressaltar que abordaremos as práticas de educar nas escolas do campo à luz das questões sobre as masculinidades, providos de uma visão ampla do objeto estudado e de um envolvimento para com a realidade social, política, econômica e cultural que o cerca. Como afirma Pais (2001, p. 110), “em ambiências qualitativas, os critérios de seleção são critérios de compreensão, pertinência e não os de representatividade estatística".

\footnotetext{
${ }^{5}$ No pós-estruturalismo, a realidade é considerada como uma construção social e subjetiva, não sendo o prefixo pós interpretado como sinal de contraposição ao estruturalismo. Como corrente filosófica, embora não constitua propriamente uma "escola", privilegia uma análise das formas simbólicas, da linguagem, mais como constituintes da subjetividade do que como constituídas por esta (SILVA, 2005).
} 


\section{Volume, 13, n. 1, ano 2017}

Entendido isso, podemos considerar que a abordagem qualitativa não se resume aos aspectos superficiais e limitados, mas permite considerar e respeitar a subjetividade dos sujeitos da pesquisa.

Sob esses caminhos metodológicos, então, nos referenciamos para investigar duas escolas de assentamentos campesino localizadas no Município de Goiás. Empreendemos, através das mídias digitais e do espaço virtual ${ }^{6}$, uma pesquisa de campo baseada na observação de discursos ${ }^{7}$ a partir de aplicação de questionários aos sujeitos de pesquisa, no caso, dois (02) sujeitos ${ }^{8}$ envolvidos. Obedecemos, para isso, às orientações éticas da Resolução 466/12 que regula pesquisa com seres humanos, cabíveis para tal procedimento. Assim, a partir dos caminhos adotados, investigamos os discursos enquanto práticas discursivas que revelam marcas do educar emergidas do masculino na experiência de educação.

Nesse raciocínio, acreditamos que é a análise dos discursos que nos permite contribuir para debates que abordam as dinâmicas e enfrentamentos do gênero masculino na educação escolar. Então, a proposta foi de ouvir e observar os discursos para que pudéssemos subsidiar nossas reflexões sobre as especificidades e subjetividades do gênero masculino na escola do campo. Trata-se, portanto, de

\footnotetext{
${ }^{6} \mathrm{O}$ uso plural do espaço virtual e de sites de relacionamentos para realização de entrevistas tem possibilitado pesquisas em ciências humanas, como descreve Santos e Dinis (2015). Temos como exemplo, nesse trabalho, o www.facebook.com. O espaço permite, uma vez marcado horário para realização das entrevistas, o uso de caixa de diálogos disponibilizada pela página citada, dando acesso às falas dos sujeitos entrevistados. Toda a dinâmica das entrevistas e armazenamento dos dados seguem as orientações dadas por Miskolci (2011) e Marcuschi (2004)
}

${ }^{7} \mathrm{O}$ discurso nesse trabalho, auxiliado por Fernandes (2012), é entendido como o que incide sobre o sujeito, tendo poder de subjetivá-lo. Como definição, o discurso não compreende somente o que é falado, mas também o silenciado e silencioso; não se restringe à palavra, conversações, texto ou escrita, mas abarca o que pode ter sentido mesmo no silêncio, naquilo que por si só pode trazer significados. Discursos são capazes de moldar e edificar o sujeito, subjetivando-o por meio das verdades que $\mathrm{o}$ atravessam.

\footnotetext{
${ }^{8}$ Os dois sujeitos de pesquisa que participaram do trabalho atuam um em cada uma das duas escolas campesinas envolvidas no projeto de pesquisa desenvolvido por acadêmic@s da Universidade federal de Goiás - Regional Goiás e intitulado: $O$ Gênero e a sexualidade na discussão: reconhecendo as diferenças para o melhor viver. Observa-se que, nas duas escolas campesinas, só há três (03) educadores do sexo masculino e um deles optou por não participar das entrevistas. $\mathrm{O}$ contato entre os pesquisadores e o corpo docente escolar, incluindo os dois sujeitos participantes, foi constante em decorrência do desenvolvimento do projeto citado. Feito o convite e uma vez aceito, foram realizadas as entrevistas via sistema digital - online.
} 
Volume, 13, n. 1, ano 2017

pesquisa de campo teve as mídias digitais como recurso metodológico facilitador para execução das entrevistas. Nesse campo de saber, há de se reconhecer que

Visando a observação de discursos, a começar como - em contraste com o passado - as novas mídias alcançam qualquer um à condição de protagonista assim como características pessoais, diferenças, passam a ser possíveis motivos articuladores de contato e socialização. [...] Trata-se de um feito nada desprezível, o qual não apenas democratiza a experiência como também a modifica profundamente em um misto de transformação técnica, social e também subjetiva. (MISKOLSI, 2011, p. 13-14).

Mediante tal raciocínio, a adoção do espaço virtual como local de pesquisa para o desenvolvimento desse trabalho, além da escola, apoia-se nos autores Marcuschi (2004) e Miskolci (2011) que consideram tal espaços adequado por ser um recurso de uso prático pluralista e de considerado potencial, ainda pouco explorado. Conforme Freitas et al. (2004), o ambiente oferece vantagens sobre alternativas de pesquisas quantitativa e qualitativa, pois permite acessar base de dados num servidor remoto, análises na própria página de relacionamentos, além de disponibilizar tabelas e gráficos.- Os participantes, portanto, ao usarem essa ferramenta e ao acessarem a página, tornam-se membros de grupos virtuais, podendo responder ao questionário ali disponibilizado. O referido questionário foi elaborado a partir das orientações dadas por Mann e Stewart (2000).

Munidos desses dados, inspiramo-nos nas teorizações de Michel Foucault $(2011$; 2008) para nossa análise dos dados emanados dos fragmentos de falas, na busca por empreender uma observação analítica sobre os discursos e suas interfaces com a verdade e o poder. Mediante tal desafio, foi preciso recusar explicações unívocas, fáceis, buscando insistentemente o sentido último e oculto das coisas, pois esta é prática bastante comum e incorreta. (FISCHER, 2001). Ao usarmos, assim, o conceito de discurso enquanto prática de produção de sentidos, ressaltamos que é preciso ficar no nível de existência das palavras e das coisas ditas e não buscar sentidos nas profundezas dos textos. Isso equivale trabalhar o discurso na sua complexidade peculiar (FERNANDES, 2012).

Sob essa ótica acerca do conceito de discurso, podemos afirmar que nada há por trás das cortinas do discurso, nem sob o chão em que se pisa. O que existem 
Volume, 13, n. 1, ano 2017

são enunciados e relações que o próprio discurso põe em funcionamento (FOUCAULT, 2008). Então, ao usar recortes de fala de professores do sexo masculino, referentes aos seus desafios, percepções e subjetividades, buscamos, enquanto educadores, apreender como os sentidos pululam nos discursos presentes nesses comentários, assim como as redes de relações históricas e práticas da questão que, inclusive, a todo tempo, são rememoradas na sociedade no campo dos debates do gênero e de masculinidade hegemônica.

\section{Fundamentação Teórica}

Iniciamos esta fundamentação argumentando que abordar docência alinhavada ao conceito de masculinidades conduz-nos a uma articulação com o conceito de gênero oriundo dos Estudos Feministas, nos Estados Unidos, os quais se desenvolveram nos anos 1960, dentro de uma perspectiva Pós-Estruturalista. Nesse sentido são empreendidas investigações no campo das relações entre o masculino e o feminino na cultura e na sociedade.

Impulsionados pelas reflexões de Judith Butler e de Michel Foucault, os Estudos de Gênero possibilitaram investigações de masculinidades e identidades, ganhando novos contornos nos anos 1980. Enquanto "saber que estabelece significados para as diferenças corporais", o gênero, segundo Scott (1994, p. 12), é discurso e trata-se de categoria socialmente imposta sobre um corpo sexuado, mas que, devido à proliferação de estudos sobre sexo e sexualidade, tornou-se palavra particularmente útil ao oferecer meios de diferenciar práticas de papéis sexuais atribuídos a cada um/a. Para Weeks,

O gênero (a condição social pela qual somos identificados como homem ou como mulher) e a sexualidade, (a forma cultural pela qual vivemos nossos desejos e prazeres corporais) tornaram-se duas coisas inexplicavelmente vinculadas. O resultado disso é que o ato de cruzar a fronteira do comportamento masculino ou feminino apropriado (isto é, aquilo que é culturalmente definido como apropriado) parece algumas vezes, a suprema transgressão (WEEKS, 1986, p. 45).

A partir da compreensão do sentido dado ao conceito de construção do gênero masculino e experiência dos corpos dos homens, o que se pode evidenciar são as múltiplas hierarquias de gênero e, ao mesmo tempo, de classe, entrelaçadas com 


\section{ITINERARUIS REFLECTIONIS}

Volume, 13, n. 1, ano 2017

projetos ativos de construção do gênero. Ressaltamos, ainda, que a masculinidade é melhor entendida a partir dos estudos da masculinidade hegemônica propostos por Connell (1995) em um estudo de campo sobre desigualdade social em escolas australianas. Nesse sentido,

A ideia de uma hierarquia das masculinidades cresceu diretamente a partir da experiência de homens homossexuais com a violência e com o preconceito dos homens heterossexuais. O conceito de homofobia originou-se nos anos 1970 e já estava sendo atribuído ao papel masculino convencional. (CONNELL, 1995, p. 244).

Para o autor, é valoroso que, ao se pensar no conceito de masculino, se proponha refletir também sobre o modelo de masculinidades em múltiplas relações de poder. Vale, entretanto, considerar que esse modelo foi sistematicamente integrado a uma teoria de gênero sociológica de masculinidade hegemônica e feminilidade enfatizada. Referencia-se nessa prática de pensar que podemos considerar o sujeito professor e, possivelmente, entender as marcas de subjetividade presentes em suas masculinidades e que lhe permitem o ajustar-se à formação e ao fazer docente. Falamos aqui do professor enquanto sujeito histórico construído, um sujeito atravessado por discursos que o moldam ao longo da vida, ajustando e modelando até seus músculos e ossos. (FERNANDES, 2012).

Quando citamos os discursos e o poder na construção do sujeito, julgamos importante, ainda, suscitar as relações de poder que a educação propiciou historicamente, como na Grécia, entre o efebo e seu mestre, ambos do sexo masculino (FOUCAULT, 2011), sendo outro exemplo a prática educativa dos padres jesuítas no Brasil colonial, marcada pela dominação e controle do saber e o poder, descrito por Gondra (2008). Podemos considerar, desta forma, que, até então, o masculino estava presente na docência e fez dela lugar privilegiado de uso dos saberes e do poder, assim como do patriarcado bem delimitado a partir dos estudos Foucault (2007). No entanto, na virada do século IX até metade do século XX na escola, o feminino passou a exercer a docência de forma crescente, ocupando tal espaço, processo que avançou até a segunda metade do século XX.

No que se refere às experiências masculinas e femininas em torno da prática do educar, não podemos ser ingênuos o bastante para pensar que as relações 
Volume, 13, n. 1, ano 2017

de poder não enredam tais experiências e práticas. Essas relações são micropolíticas, moleculares, atravessam e constituem sujeitos. Por ser assim, questionamos: como as relações de poder instituem práticas de educar e como essas práticas são, na sua singularidade, atravessadas pelas masculinidades? Eis uma problemática que salta aos nossos olhos!

Para enveredar por algumas hipóteses que possam responder a essa pergunta, não podemos deixar de destacar implicações em torno da relação entre o feminino e as práticas de educar, e como a emergência do masculino nessas práticas construíram outras experiências possíveis. Nesse campo, Louro (1997) nos auxilia a entender que, no Brasil, o ajuste seguiu a tendência do mundo ocidental do fim do século XIX, contexto em que a presença da mulher na escola, como aluna e professora, era tida como fundamental. Nesse período, o magistério passou a ser concebido como profissão feminina. Conceitualmente, para a autora, a mentalidade era que o ensino estava adaptado à natureza feminina sendo preparação ideal para o papel de mãe de família. O mesmo também foi observado em países como Inglaterra, Estados Unidos, Portugal, França e Canadá, dentre outros.

Nota-se que emerge, rememora e fortalece-se nesse período um discurso de valorização da afetividade ${ }^{9}$ feminina. Essa conceituação volta-se, por outro lado, para a escola enquanto, ao mesmo tempo, o masculino é reconhecido como hegemônico e heteronormativo, esperado, marcado pela rigidez nas condutas e destituído de sensibilidade e valorizado nas mulheres. Tratavam-se de marcas que tornavam homens inadequados para a escola e o labor docente. Todavia estudos recentes sobre masculinidades nos subsidiam a indagar a dinâmica que envolve o masculino e sua construção, assim como o ajuste de dadas masculinidades à docência.

\footnotetext{
${ }^{9} \mathrm{O}$ termo afetividade procede do latim afficere, afectum, produzir impressão. Para Herculano (2011 p. 116), professores se percebem como educadores e gostam de cuidar do aluno. No entanto, esse seu compromisso esbarra na dificuldade que eles têm de reconhecer e dominar os afetos negativos que emergem na convivência com seus alunos. Vimos que o docente suplica por respeito, e muitos deles têm dificuldade de manter uma relação de autoridade em sala de aula. Todos acreditam que o diálogo é uma grande estratégia para melhorar o vínculo com os discentes, entretanto descobrimos que muitos docentes não compreendem a diferença entre rigor e rigidez. Eles passam a ser considerados "chatos" por alguns alunos, acreditando que, com tal postura de cobrança sem negociações, estariam agindo de maneira rigorosa quando, de fato, estão agindo de forma autoritária e rígida, o que demonstra a falta de competência para resolver problemas referentes à dinâmica da sala de aula.
} 


\section{ITTMERAPUUS REFLECTIONIS}

Volume, 13, n. 1, ano 2017
DA GRADUAÇÃO/PÓS - GRADUAÇÃO EM EDUCAÇÃ O

ISSN. 1807-9342

Portanto, antes de adentrarmos as questões que envolvem a formação docente e os aportes teóricos para tal, nos atentaremos ainda na melhor delimitação do masculino e o que entendemos como masculinidade.

O masculino, em termos comuns, se refere à imagem de tudo aquilo que seria próprio de indivíduos "machos", os que possuem qualidades ou características consideradas típicas ou necessárias para o homem. De forma pormenorizada, Santos e Dinis (2013) e Santos (2016) definem que o masculino tem a ver com o fazer masculino e Connell (1995) ainda acrescenta que se trata de uma construção social e discursiva, elaborada por interações por vezes, de natureza conflituosa, complexa e relativamente precária. Seria uma configuração de prática em torno da posição dos homens na estrutura das relações de gênero.

No que se refere às teorias que subsidiam a discussão do masculino, é importante arrazoar que não se deve falar de masculinidade e sim de masculinidades, devido a sua pluralidade de formas. Nesse campo, ao investigar sobre o que poderia ser entendido por masculinidades, o autor ainda orienta que deve-se deixar as definições breves e centrar-se na conceituação razoavelmente precisa.

Ainda considera que,

A masculinidade é uma configuração de prática em torno da posição dos homens nas estruturadas relações de gênero. Existe normalmente, mais de uma configuração desse tipo em qualquer ordem de gênero de uma sociedade. Em reconhecimento desse fato, tem-se tornado comum falar de "masculinidades" (CONNELL, 1995, p.188).

A masculinidade, sob essas perspectivas, não é singular, mas plural e, inserida numa perspectiva de gênero, é muito mais ampla do que simples definições dadas na biologia. Sendo assim, é complexa, não natural e engloba economia, estado, família e sexualidade. Assim, a passagem do termo masculinidade para masculinidades não é algo simples e desprovido de implicações, mas confirma o enraizamento cultural do gênero e menciona sua imersão nas relações de poder e dinâmica biopolítica da sociedade. (SANTOS, 2016). Deste modo, pode-se afirmar que a masculinidade é construção cultural e suas raízes estão fundamentadas na história e nas políticas de gênero. Nesse campo, é Connell (1995) quem afirma que há políticas de gênero que conduzem múltiplas relações de aliança, de dominação e subordinação entre diversas masculinidades. 
Volume, 13, n. 1, ano 2017

Nessa perspectiva de edificação do masculino enquanto gênero, Foucault (2007) afirma que os corpos dos homens são como um corolário da produção de verdade dentro dos discursos, tornando-se objetos sobre o qual eles e sociedade trabalham por meio de práticas corporais no dia a dia. Isso nos conduz a considerar os possíveis ajustes do masculino à pratica docente e ambiente escolar proporcionais às subjetividades que trazem de suas construções enquanto sujeitos.

Sobre a hegemonia citada por Connell (1995), é preciso ainda perceber e reforçar que um padrão de masculinidade não significa controle total das demais possibilidades e que isso também não impossibilita o fato de estarem ou serem submetidas a crises. Mas para tal, como afirma Foucault (2004), temos as rotas de fuga ${ }^{10}$. Elas seriam arranjos de certas masculinidades, consequência das necessidades de sentirem-se não correspondentes ao discurso divulgado e aceito para a masculinidade esperada e normatizada. Assim, construídas e consequência dos difíceis ajustes é que certas masculinidades não hegemônicas podem encontrar na docência possíveis rotas de fuga e ajuste para a profissionalização. Essas considerações encontram respaldo nas afirmações a seguir ao considerar que,

As masculinidades hegemônicas podem ser construídas de forma que não correspondam verdadeiramente à vida de nenhum homem real. Mesmo assim esses modelos expressam, em vários sentidos, ideais, fantasias e desejos muito difundidos. Eles oferecem modelos de relações com as mulheres e soluções aos problemas das relações de gênero. Ademais, eles se articulam livremente com a constituição prática das masculinidades como formas de viver as circunstâncias locais cotidianas. Na medida em que fazem isso, contribuem para a hegemonia na ordem de gênero societal. Não é surpreendente que homens que funcionam como exemplos no nível regional[...] exibam contradições (CONNELL, 2013, p. 253).

\footnotetext{
${ }^{10}$ Referenciadas em Foucault (2004), as rotas de fugas fazem parte das estratégias do cuidado de si e podem ser bem entendidas a partir da obra Hermenêutica do Sujeitos, (FOUCAULT, 2011). Trata-se de arranjos sociais que são consequência das necessidades e vivências de cada um e nem sempre correspondem ao discurso divulgado e aceito. Seriam construídas em consequência dos difíceis ajustes.
} 
Volume, 13, n. 1, ano 2017

Nesse caminho, historicamente vêm de Badinter (1999), Connell (1995) e Miskolci (2009) sinalizações tanto sobre a criação das masculinidades quanto das rotas de fuga e suas dinâmicas nas relações sociais do presente e também entendimentos de como podem ser estabelecidas. Reiterando o que já foi dito e refazendo a indagação: A educação, como campo de profissionalização, seria uma rota de fuga para masculinidades não hegemônicas sujeitas aos processos de subalternização? Essas masculinidades encontram nesse campo profissionalizante um lugar de conhecimento e convívio com menor rejeição ou subalternização menos intensa?

Como resposta, vale ressaltar a percepção sobre o masculino e os estudos nesse campo os quais, mesmo antes do movimento de liberação das mulheres, da abordagem da literatura sobre o papel sexual do homem na psicologia social e na sociologia, já distinguiam que forma se daria à natureza social da masculinidade e às possíveis transformações da conduta dos homens, proporcionais às necessidades e ajustes exigidos. Então, confirma que ajustes ocorrem e nisso, basta que consideremos que,

A maneira como cada um que ensina está diretamente dependente daquilo que somos como pessoas quando exercemos o ensino [...] Eisnos de novo face à pessoa e ao profissional, ao ser e ao ensino. Aqui estamos. Nós e a profissão. E as opções que cada um de nós temos de fazer como professor as quais cruzam a nossa maneira de ser com a nossa maneira de ensinar e desvendam na nossa maneira de ensinar a nossa maneira de ser. É impossível separar o eu profissional do eu pessoal (NÓVOA 2000, p. 17).

Nessa dinâmica do masculino e de seu ajuste na e para a educação, no porquê do retorno gradativo do masculino às licenciaturas e práticas docentes escolares no fim do século XX, sabemos também que, ao longo dos anos 1970, houve uma explosão de escritos sobre o papel do masculino, claramente criticando as normas referentes aos papéis, como a origem do comportamento opressivo dos homens. Foi a crítica da teoria dos papéis que forneceu a base conceitual principal para o primeiro movimento de homens antissexistas. Ressaltamos também que, inclusive, as leituras referentes aos corpos como objeto dos processos de construção social, tradicionais nas ciências sociais, têm sido consideradas amplamente inadequadas. Com referência aos ajustes, vale consideração de Connel:

Os corpos estão envolvidos mais ativamente, mais intimamente e mais intrinsecamente em processos sociais do que a teoria usualmente lhes 
Volume, 13, n. 1, ano 2017

permitiu. Os corpos participam na ação social ao delinearem os cursos da conduta social - o corpo como participante da geração de práticas sociais. É importante que não apenas as masculinidades sejam entendidas como incorporadas, mas também que sejam tratados os entrelaçamentos das incorporações com os contextos sociais. (CONNELL, 1995, p 269).

$\mathrm{O}$ autor ainda afirma a existência, dentro dos grupos sociais, de padrões específicos de masculinidades mais respeitados que outras, o padrão hegemônico, acrescentado que as masculinidades estão por todo tempo em processo de construção em cada um. Nisso, confirma-se que

A masculinidade não se adapta simplesmente às condições de transformação histórica. Em vez disso, [...] é uma hibridização cuja apropriação de elementos diversos o faz "capaz de se reconfigurar e adaptar às especificidades de novas conjecturas históricas". [...] a visibilidade da masculinidade gay nas sociedades ocidentais fez com que se tornasse possível para muitos homens heterossexuais se apropriarem de "partes e pedaços" dos estilos e das práticas de homens gays e construírem uma nova configuração híbrida de prática de gênero. (CONNELL, 2013, p. 261).

Gostaríamos de considerar que são tipos específicos de masculinidades e não outras que melhor atendem as demandas da educação, assim como a essa profissionalização, tornando a docência um caminho de ajuste para uns e, possivelmente, surgindo como alternativa e rota de fuga que viabilizaria a assumência de um lugar de masculinidade cambiante e subalterna, ou seja, tolerada devido à aceitação e à eficiência profissional que se possa alcançar. Isso pode ser confirmando quando consideramos que

Na subjetividade social da escola, além dos elementos de sentido de natureza interativa gerados no espaço escolar, se integram à constituição subjetiva deste espaço elementos de sentido procedentes de outras regiões da subjetividade social, como podem ser elementos de gênero, de posição socioeconômica, de raças, costumes, familiares etc., que se integram com os elementos imediatos dos processos atuais da escola (GONZÁLEZ REY, 2005, p. 203).

Pelos dados descritos, poderíamos arrazoar que a educação é um caminho de rota de fuga para dadas masculinidades não hegemônicas, as quais por tratarem-se de tipos específicos de subjetividade masculina, estão na sociedade diluídas em meio às demais masculinidades. É ainda Connell (1995) quem nos permite reafirmar que a produção de um tipo particular de masculinidade exemplar requer uma luta política e, consequentemente, a derrota de outras masculinidades alternativas. Mas, buscando 


\section{TTMERARUUS REFLECTIONIS}

Volume, 13, n. 1, ano 2017

melhor entender a profissionalização docente masculina e seu ajuste a esse oficio, tomaremos como referência conceitos comuns adotados nas licenciaturas. Nos processos de formação de professores e professoras no Brasil de nosso tempo.

\section{Discutindo saberes docentes na perspectiva de três autores}

Ao reunirmos em nossas reflexões sobre os saberes docentes, ou o pensamento de Tardif (2002), Shulman (1986) e Perrenoud (2000), consideramos, inicialmente, que o pensar dos mesmos, expresso em suas publicações, apresenta consideradas singularidades. Nesse sentido, Tardif (2002) pondera os saberes docentes como fundamentais a quem educa, sendo conhecimentos, competências, habilidades e atitudes a serem usadas no cotidiano profissional. Nesse sentido, ele cita a importância dos limites e possibilidades que são apresentados no contexto da docência e a forma como influem no melhor ou no pior ajuste do trabalho docente, questão que, afirma ele, é comum a todo docente.

Tardif (2002) ainda sinaliza que os saberes docentes podem ser compreendidos a partir de quatro aspectos ou perspectivas: os saberes temporais, experienciais, curriculares e disciplinares. Fornecendo explicações, os saberes experienciais se tornam reconhecidos a partir do ponto em que docentes expressam suas ideias referentes aos saberes curriculares e disciplinares e, principalmente, em relação a sua própria formação continuada. Quanto ao campo curricular, Tardif (2002) chama a atenção para o respeito aos programas escolares, avaliando que

Professores precisam interpretá-los e transformá-los em função das condições concretas da turma e da evolução das aprendizagens dos alunos. Quer se trate de uma aula ou do programa a ser ministrado durante o ano inteiro, $[\ldots]$ o professor precisa mobilizar um vasto cabedal de saberes e habilidades, porque sua ação é orientada por diferentes objetivos: [...] ligados à motivação dos alunos, [...] ligados à disciplina e à gestão da turma, $[. .$.$] ligados à aprendizagem$ da matéria ensinada, [...] coletivos ligados ao projeto educacional da escola, etc. (Tardif, 2002, p.264).

Pelo descrito, fica evidenciado que os saberes profissionais docentes são temporais. E, por serem assim, são construídos ao longo da vida, a partir da história cultural e escolar de cada sujeito. Soma-se a isso a formação profissional e as experiências que se tem, pois tais pressupostos coadunam com os princípio históricocultural de formação do sujeito. 


\section{Volume, 13, n. 1, ano 2017}

Quanto à prática de educar, para Tardif (2002), esta compreende o ser como ator social, sendo ideal que ele possa decidir, escolher e agir com base em seus recursos, capacidades e subjetividades. O sujeito 2 da pesquisa, ao falar de sua relação com a educação, exemplifica tal questão.

Eu penso que minha realização como professor está na capacidade não só de transmitir os conteúdos programados na grade curricular, mas também saber ouvir e me envolver com diferentes situações em sala de aula. Em sala de aula acaba a preocupação com os desafios diários que temos com família, sociedade e as partes burocráticas. Lá eu me envolvo extremamente. $O$ que me realiza é saber que contribuo para formação de diversos sujeitos.

O discurso sobre o saber docente neste fragmento reúne aspectos específicos como a "capacidade" de "transmitir conteúdos programados na grade curricular", e o "ouvir" e "envolver com diferentes situações em sala de aula". São saberes construídos a partir da experiência docente, e não apenas adquiridos na formação inicial. Nessa experiência prática de educar, Sujeito 2 reconhece que tais saberes libertam da rede ordinária de outras atividades que inscrevem-no no cotidiano com a família, a sociedade e a burocracia. Assim, a sala de aula e seu princípio formador tecem outros conjuntos de relações completamente singulares. Os saberes docentes perfazem esse campo discursivo singular, específico e fabricador de uma experiência docente não tão alinhada às normas impostas.

É nesse campo de contravenção e de fuga à norma que percebemos a importância de se observar a afetividade como um traço poderoso e fundamental para o fazer docente. Tal afirmativa de busca por autonomia contrasta com a tecnicidade, a objetividade e o pragmatismo presentes e impressos nos currículos, sendo posicionamentos que dificilmente contemplam ou valorizam a importância do afetivo na educação. O professor ou a professora que operam com esses recursos da sensibilidade e da afetividade, mobilizados ao longo de seus saberes docentes, recusa a ordem discursiva que instala fazeres técnicos, objetivos e pragmáticos. Assim, não há como recusar a estreita relação, através dos saberes docentes, entre o afetivo e o educar.

Pelo descrito, a afetividade referida baseia-se e sustenta-se em saberes e traços de componentes éticos e emocionais, mediante as necessidades discentes e 


\section{ITTMERARUIS REFLECTIONIS}

Volume, 13, n. 1, ano 2017
REVISTA ELETRÔNICA

DA GRADUAÇÃO/PÓS-GRADUAÇÃO EM EDUCAÇÃO

ISSN. 1807-9342

mesmo docentes e cada contexto de vida. Nesse sentido, é o mediar do saber no ato de educar que deixaria transparecer tal afetividade, através de atitudes, gestos ou expressões corporais, proporcionais às verdades de quem educa. É isso que alcança substancialmente as relações que permeiam a interação dos sujeitos que interagem nessa ação e, referimo-nos aqui aos docentes e discentes. (LOURO, 2008). São esses elementos conectados que formarão uma espécie de rede de sustentação dos saberes dos docentes onde vinculam-se conhecimentos, emoções, intuições e representações sociais. Sob a ótica de Moraes e Torres (2004):

A aprendizagem humana, quando é integrada, comporta elementos emocionais, intuitivos, atitudinais, e inclusive sociais. [...] É fruto de interações com a cultura socialmente enriquecedora. [...] As aprendizagens variam com as pessoas que vivem no entorno, com a motivação intrínseca, com o clima de interação criado e com o próprio conteúdo, objeto da aprendizagem. Assim, pois, a aprendizagem integrada tem sua razão de ser nos componentes cognitivos, sócio-afetivos e culturais (MORAES; TORRE, 2004, p. $85)$.

Mas, sem negar a perspectiva técnica de saberes docentes, podemos nos apoiar nas considerações feitas por Shulman (1986). Este autor demanda-nos refletir sobre a prática docente e, nesse campo, analisa de que forma é possível balancear os saberes relacionados ao conteúdo e ao processo de ensinar. Para isso, ele propõe três diferentes categorias de saberes construídos para a docência como fundamentais para a formação docente: os saberes disciplinares, os pedagógicos e os curriculares. Segundo ele,

Nós estamos obtendo um corpo sempre crescente de conhecimento sobre erros conceituais dos estudantes e sobre as condições de instrução necessárias para transformar e superar estas conceituações iniciais. Este conhecimento baseado em pesquisa, [...] deve aparecer no âmago de nossa definição do conhecimento pedagógico necessário". (SHULMAN, 1986, p. 10)

Sob a ótica de Shulman (1986), os saberes docentes são forjados mediante pesquisas empreendidas nas práticas pedagógicas diárias. Para o autor, são nessas práticas de pesquisar que construímos conhecimentos sobre erros conceituais e sobre as transformações cognitivas dos alunos em processo de superação das conceituações iniciais. Alinhavados aos saberes disciplinares, o autor ainda explicita que estes estão 


\section{ITTMERARUUS REFLECTIONIS}

Volume, 13, n. 1, ano 2017

relacionados aos conceitos e dados que envolvem o conteúdo, acrescentando, ainda que, quando definidos como saberes pedagógico-disciplinares, eles estão ligados à prática do que se ensina e como se ensina. Seria a utilização e aplicações, assim como as ilustrações e analogias, de modo a tornar o que se está ensinando compreensível aos estudantes. No que se refere aos saberes curriculares, estes, para Shulman (1986), relacionam-se com aquilo que é obtido pelo conhecimento e análise das orientações curriculares já existentes e que estão associados aos conteúdos e métodos a partir dos quais a escola categoriza e se organiza.

Vale ressaltar que a procedência, composição e a decisão do que fica fora ou não dos currículos, embora estes cheguem e estejam na escola, é decisão que fica a cargo do cientista que produz tal saber nos centros acadêmicos. Podemos dizer que há, aí, um jogo de poder e de interesses diversos, pois os currículos estão sempre sujeitos aos interesses políticos e econômicos, proporcionais aos contextos em que serão e estão inseridos. No que se refere ao conhecimento pedagógico disciplinar, consideremos também que ele inclui uma compreensão do que faz a aprendizagem de um dado tópico ser fácil ou difícil. Para tal afirmativa, há de se levar em consideração as concepções e percepções de educandos de diferentes idades e origens. Nessa consideração,

O currículo é representado pela amplitude dos programas planejados para o ensino de disciplinas escolhidas, pela variedade de materiais instrucionais colocada à disposição, e o conjunto de indicações e contraindicações para o uso de um determinado currículo ou materiais em circunstâncias particulares. Podemos esperar que o professor experiente possua esta compreensão sobre as alternativas curriculares à sua disposição (SHULMAN, 1986. p. 10)

As descrições do autor acerca do ensino planejado, da diversidade de conteúdos e das possibilidades em torno da necessidade de se obedecer o que indicam os currículos, dando conta das re-invenções das práticas em torno das contraindicações, valorizam a formação continuada enquanto alternativa curricular para docência. Talvez isso ocorra devido ao fato de a observação da prática docente escolar viabilizar o perceber de erros, omissões e êxitos, implementando, a partir disso, uma melhor a formação inicial e auxiliar à superação dos desafios de quem já está atuando. Sendo assim, o pensar de Shuman (1986) coaduna com o de Tardif (2002) naquilo que implica no fracasso da formação docente e atuação na escola. 


\section{ITTEEARUUS \\ REFLECTIONIS}

Volume, 13, n. 1, ano 2017

A partir do pensamento dos autores, ainda, é possível considerar algumas fragilidades: currículos voltados a atender demandas de mercado e distantes da realidade de quem o aprende e ensina; as condições de trabalho docente na escola; a precarização docente e do ensino no sentido de verbas e salários; o sucateamento das licenciaturas; o tecnicismo excessivo presente nos processos de formação inicial de professor@s; a precária formação cultural e socioeconômica dos licenciand@s; o demérito dos saberes pedagógicos em detrimentos da valorização excessiva dos saberes científicos e vice versa; a forma como os saberes podem estar alocados em disciplinas, dificultando a interdisciplinaridades dos mesmos, dentre outros.

Ao se referir a tais questões, Shulman (1986) e Tardif (2002) afirmam que docentes que desconhecem os conteúdos que ensinam estão fadado ao fracasso. O mesmo ocorre com quem desconhece estratégias pedagógicas que impossibilitam a aprendizagem. Assim, para a formação docente, seria importante ter em mente os saberes disciplinares cognitivos, afetivos e sociais. Ao fazer tais considerações, as perspectivas referenciadas nos dois autores novamente suscitam a importância da afetividade como um marco da docência e fundamental para seu êxito.

Shulman (1986) ainda reforça que é a articulação dos saberes, num processo interdisciplinar, que propicia práticas de ensino bem-sucedidas. Com isso, na concepção do autor, seria a possibilidade de gerir sua própria formação, subsidiada por uma percepção pormenorizada de seus desafios no ensinar, que viabilizaria uma melhor formação aos futur@s docente. Nesse sentido, é preciso

Saber explicitar as próprias práticas. Estabelecer seu balanço de competências e seu programa pessoal de formação contínua. Negociar um projeto de formação, acolher e participar da formação dos colegas. ( SHULMAN, 1999, p.16)

$\mathrm{O}$ autor ainda adverte que, no ensino, é importante e fundamental considerarmos os aspectos do processo de onde alguém parte da compreensão pessoal para a preparação da compreensão do outro. Para ele, aí está a importância da formação cultural docente. Nesse sentido, o autor afirma que em tal execução a essência da ação e do raciocínio depende do planejamento e da construção adequada e correta do conhecimento. Portanto, as habilidades técnicas sem conhecimento do que se ensina não tornam a docência bem-sucedida, devido ao repasse errado do saber ensinado. Da mesma 


\section{ITINERARUIS REFLECTIONIS}

Volume, 13, n. 1, ano 2017

REVISTA ELETRÔNICA

DA GRADUAÇÃ O/PÓS-GRADUAÇÃO EM EDUCAÇÃ O

ISSN. 1807-9342

forma, os domínios do conhecimento sem as habilidades para o ensino contribuem para o fracasso.

Nesse campo de raciocínio, em consonância com Tardif (2002), percebemos a valorização das complexas competências importantes ao educar, mostrando as exigências de múltiplas habilidades e o fundamental entrelaçar das mesmas. Shulman (1986) concorda com tais colocações e expõe tratar-se de questões singulares para a formação. Para além disso, o autor valoriza a importância de haver articulação com o processo do ensino e do saber a ser ensinado. Perrenoud (2000), como que dando sequência a tais considerações, ainda vem alertar sobre a complexidade das competências e a diversidade das mesmas.

Para o autor existem dez competências exigidas para o educar e ele as categoriza da seguinte maneira: o organizar e digerir situações de aprendizagem; o administrar a progressão das aprendizagens; o conceber e fazer evoluir os dispositivos de diferenciação; o envolver os alunos em suas aprendizagens e em seus trabalhos; o trabalhar em equipe; o participar da administração da escola, saber informar e envolver os pais; o se lançar no desafio de utilizar novas tecnologias, enfrentando os deveres e dilemas éticos da profissão e ainda sabendo administrar sua própria formação continuada. Nesse sentido, o autor cita a importância de

Se organizar e animar situações de aprendizagem, trabalhar a partir das representações dos alunos, trabalhar a partir dos erros e dos obstáculos de aprendizagem (...) administrar a progressão das aprendizagens conceber e administrar situações-problemas de acordo com os níveis e possibilidades dos alunos conceber e fazer evoluir dispositivos de diferenciação administrar a heterogeneidade no interior de um grupoclasse eliminar a separação, ampliar a gestão da classe para um espaço maior (PERRENOLD. 1999, p.16).

O que pode ser percebido é que o pensamento do autor coaduna com as considerações feitas por Pimenta (1999), quando este afirma que a importância de preparar professores que assumam uma atitude reflexiva em relação ao seu ensino e às condições sociais que o influenciam é algo a ter relevância nas licenciaturas. A autora afirma que a tendência investigativa na educação valoriza o professor. É nessa perspectiva que

O profissional mobiliza um capital de saberes, de saber-fazer e de saberser que não estagnou, pelo contrário, cresce constantemente, 


\section{ITTMERARUUS \\ REFLECTIONIS}

Volume, 13, n. 1, ano 2017
DA GRADUAC ÃO/PÓS-GRADUAÇÃO EM EDUCAÇÃO

ISSN. 1807-9342

acompanhando a experiência e, sobretudo, a reflexão sobre a experiência [...] a reflexão sobre a própria prática é, em si mesma, um motor essencial de inovação (PERRENOLD, 1999, p. 186).

Portanto, consideremos a experiência não somente a aprendida nas licenciaturas, mas o saber vivenciado pelos alunos durante a escolarização. Que valorizem-se também os saberes produzidos no cotidiano da atividade docente. Isso porque, pelas considerações feitas, os saberes pedagógicos seriam produzidos na ação, a partir do contato com os saberes sobre a educação e sobre a pedagogia, no quais se encontram instrumentos para construir práticas e os saberes do conhecimento. Ainda, vem de Perrenold (2000) e é endossada por Pimenta (1999) a sinalização da importância e do significado do conhecimento, assim como de seu sentido na vida das pessoas, não sendo diferente na formação docente e no seu fazer.

Percebemos, portanto, que, como considerado referencial para os estudos que envolvem saberes docentes e formação profissional, o pensar de Tardif (2002), Shulman (1986; 1995) e Perrenold (2000; 1999), mesmo que apresentado aqui de forma breve, proporciona entendimentos do que tem sido adotado, usado e direcionado às licenciaturas. Fica perceptível na breve explanação do pensar desses autores, além disso, a forma como cada um discute e subdivide os saberes docentes e como algumas questões citadas entrecruzam-se entre os três autores. Nisso, podemos considerar que o fazer docente não é de fácil ajuste, exige múltiplas perspectivas, estratégias e ações e não começa nem se encerra nas licenciaturas.

\section{As masculinidades subalternas e a docência como profissionalização}

Para adentrar o tema das masculinidades subalternas e a docência como profissionalização, retomamos aqui o conceito de sensibilidade articulada à construção da prática docente junto ao processo de edificar de habilidades e competências. Pelo que já foi descrito nos estudos de masculinidade, pensar em subjetividades masculinas marcadas por sensibilidade é entendê-las como subalternas, cambiantes, distantes do padrão esperado, podendo não serem reconhecidas como masculinidade hegemônica. Nesse sentido, é o conceito de hegemonia masculina que nos auxiliará na edificação de entendimentos das dinâmicas que levam certas masculinidades a identificarem-se com profissionalização docente. Connel esclarece: 
Volume, 13, n. 1, ano 2017

O conceito de masculinidade hegemônica tem sido usado em estudos na educação para compreender as dinâmicas da vida em sala de aula, incluindo os padrões de resistência e bullying entre meninos. Foi usado para explorar as relações com o currículo e as dificuldades da pedagogia neutra de gênero. Foi usado para entender as estratégias e as identidades de professores em grupos, tais como os de instrutores de educação física. [...] Eventualmente os esforços em crescimento de pesquisas tendiam a expandir o conceito. Essa imagem pode ser vista em quatro formas principais: pela documentação sobre as consequências e os custos da hegemonia, pelo Desvelamento dos mecanismos da hegemonia, pela demonstração da vasta diversidade de masculinidades e pelo delineamento das transformações nas masculinidades hegemônicas (CONNELL, 2013, p. 246 - 247).

À luz destas considerações, é possível afirmar que o professor usa de múltiplas marcas presentes nas masculinidades não hegemônicas ${ }^{11}$, tidas como masculinidades subalternas para tornar-se professor e ser bem-sucedido e, com isso, ajustar-se às diferentes formas e contextos na escola. Percebe-se, no entanto, a partir da leitura do fragmento a seguir, que há preconceito, mas pode-se optar por não se preocupar com a questão.

Trabalhando onde trabalho, penso que as nossas docentes têm uma maturidade em nível de conhecimento que não tem esse tipo de atitude de preconceito para com o professor homem. Talvez pense mais não falam, não consigo detectar. Sobre minha preocupação com tais questões, mesmo se não tivesse passado por constrangimento eu iria valorizar. Até porque eu acredito na liberdade de escolha (Sujeito 2).

Ao considerarmos a realidade singular em que vive profissionalmente o Sujeito 2, notamos que as imagens das quais ele lança mão suscitam a presença de experiências docentes onde homens e mulheres trabalham equitativamente na educação. Pelos recortes de fala, inexistem preconceitos e, se os existissem, sua posição seria o de valorizar a liberdade de escolha de cada um. Então, há de se questionar a inexistência de discursos preconceituosos no ambiente escolar e o enfrentamento com que se lida com a

\footnotetext{
${ }^{11}$ Para Santos (2016), masculinidades não hegemônicas são aquelas que estão no campo da subalternidade. Tratam-se dos que temem ser punidos ou excluídos e, por isso, se autovigiam constantemente. Mas, medo de quê? De acordo com Michael Warner (1991), seriam os denominados como fora da norma, subalternos, clandestinos, ilegais ou anormais. Para Miskolci (2009), refere-se aos que estão na margem e, por isso, são excluídos, restando-lhes o caminho de ajustar-se ou negar-se. Sobre a masculinidade hegemônica, o termo é usado por Robert W. Connell em seus estudos (1995; 2013).
} 


\section{ITTMERARUUS REFLECTIONIS}

Volume, 13, n. 1, ano 2017

REVISTA ELETRÔNICA

DA GRADUAÇÃ O/PÓS-GRADUAÇÃO EM EDUCAÇÃ O

ISSN. 1807-9342

questão que é o diferencial. Nisso, cabe considerar a forma hegemônica atribuída a um tipo de masculinidade e, segundo Connell (1995; 2013), a existência de outras masculinidades agrupadas em torno dela, visto que existem diferentes formas de usar, sentir e mostrar-se masculino. A fala a seguir confirma e vem ao encontro de tal preposição. Nesse sentido, o sujeito assim afirma:

Penso isso pela questão de que muitos homens acham que eles têm o papel definido na sociedade tipo trabalhar constituir família e assim por diante. Na escola campesina isto se reforça muito com a criação dos pais e o que é repassado aos filhos. Eu penso que isso se dá por não terem esclarecimento necessário para discutir sobre o tema (Sujeito 2).

A leitura de Sujeito 2 acerca do trabalho docente encampa concepções de masculinidades ancoradas na posição hegemônica, segundo a qual a educação é direcionada para a constituição de famílias heteronormativas, capazes de reproduzir o sistema de dominação masculina. Aos homens, o trabalho, a constituição de família e a garantia de que esse sistema seja reproduzido mediante a educação dos filhos. Isso é o que se espera, a partir dos recortes de fala de Sujeito 2, dos entrecruzamentos entre a experiência docente e a masculinidade. Masculinidade essa passível de operar várias frentes, várias imagens, várias experiências.

Em suma, masculinidade não! Masculinidades! Confirmando esse posicionamento, Santos e Dinis (2013) e Santos (2016) auxiliam o entendimento de que os homens, assim como o recorte de fala sinaliza, podem se utilizar de múltiplas formas de masculinidade e se esquivarem de outras, de acordo com sua necessidade e, ainda, se utilizarem de traços da masculinidade hegemônica quando convier e viceversa. Portanto,

Os homens podem adotar a masculinidade hegemônica quando é desejável, mas os mesmos homens podem se distanciar estrategicamente da masculinidade hegemônica em outros momentos. Consequentemente, a "masculinidade" representa não um tipo determinado de homem, mas, em vez disso, uma forma como os homens se posicionam através de práticas discursivas. (CONNEL, 1995. P 257).

Tais considerações permitem perceber que a educação, ao exigir a sensibilidade como traço subjetivo importante ao seu exercício, pode sim encontrar 


\section{ITTMERARUUS REFLECTIONIS}

Volume, 13, n. 1, ano 2017

nas identidades masculinas possíveis ajustes, mesmo que, ao longo desse processo, ocorram diversas situações e posicionamentos contraditórios e discriminatórios. O recorte a seguir contribui para melhor entendimento disso.

Eu notei que há constrangimentos no curso destinados a gestores que participei. Isso ficou perceptível. As professoras acreditam que tudo gira entorno delas e se algo não agrada, vira falatório e muitas vezes causam constrangimentos porque não aceitam nosso pensamento. Então adotamos a política de boa vizinhança, concordamos para não entrar em atrito com colegas de trabalho (Sujeito 1).

Entre ajustes, situações e posicionamentos paradoxais, o recorte da fala do Sujeito 1 suscita-nos uma percepção da masculinidade associada a múltiplas dimensões no que se refere à prática da gestão, mostrando-nos as práticas das mulheres nessa experiência. Isso demonstra que nem sempre as adequações entre o labor docente e a masculinidade seguem uma linha de aproximação. Então, mesmo que entendidos como inadequados ao labor docente por quem já está no ofício, o recorte de fala mostra que homens podem se distanciar do normativamente estabelecido, proporcional às situações que vivem, se ajustando e persistindo em seu labor, atendendo à demanda e exercendo sua profissão. Há considerações teóricas que vem confirmando isso. Pois,

Finalmente, um corpo considerável de pesquisas mostra que as masculinidades não são simplesmente diferentes entre si mas também sujeitas a mudanças. Desafios à hegemonia são comuns, e o são também os ajustes em face desses desafios (CONNELL, 2013, p. 248).

Nisso, podemos considerar que as masculinidades tidas como subalternas podem estar encontrando na educação de nosso tempo um possível ajuste para o processo de profissionalização. Nesse sentido, as descrições sobre subalternidade masculina e o estranhamento das mesmas na educação mostram-se na narrativa do sujeito a seguir ao afirmar que

No início da carreira vivi constrangimentos, quando comecei na educação. Um belo dia num povoado que lecionei, estava conversando e um homem matuto me chamou de viado, pois falava manso e um português mais coerente. Fiquei triste porque que estas pessoas pensam o homem para ser homem tem que ser grosso (Sujeito 2). 


\section{ITTEERARUS \\ REFLECTIONIS}

Volume, 13, n. 1, ano 2017

O relato acima é carregado de sentidos. Nele, percebemos a emergência da imagem do professor construída por sujeitos não docentes, como qualquer vivente em alguma região do interior do Brasil. Esses sujeitos, provavelmente, estão ancorados na experiência de masculinidade hegemônica, somados à condição de desprovidos da habilidade de usar a linguagem padrão correta e, longe de operarem seu trabalho com instrumentos leves, como canetas, lápis, giz e cadernos. Vale considerar que os detentores destas habilidades são associados à condição de masculinidade desajustada, relacionada à homossexualidade, portanto, subalterna.

Estaria aí o relato como descrição de uma rede de poder que dispõe em posições hierarquizadas: o professor e o trabalhador braçal e, possivelmente, do campo. Posições essas que encerram o professor em condição considerada como inferior, como a de "viado". Sob a ótica do matuto, o falar grosso e o uso da linguagem adaptado às regionalidades é sinal de masculinidade posicionada em condição superior e mais hábil e liberdade para o exercício de poder.

Nesse sentido, buscando amarrar a discussão feita sobre o masculino, seu reconhecimento enquanto diversidade e discussão importante para o debate de formação docente, asseguramos que, ao fazer tais considerações, não temos a pretensão de adentrar as questões da sexualidade e docência, mesmo reconhecendo que, ao discutir gênero masculino, seja desaconselhável desassociá-la das questões da sexualidade. Mas reconhecemos, sim, que estudos de gênero solicitam saberes sobre sexualidade ao tomarmos o relato do professor sobre o homem matuto como uma descrição que associa a docência às práticas da sexualidade. Por isso, reforçamos que as práticas sexuais estão inscritas no gênero e revelam símbolos que socialmente conferem forma para diferenças que ilustram o feminino e o masculino em culturas díspares, inclusive as relações existentes entre as escolas e comunidade local.

Mas, consideramos que é o conhecimento nesse campo, disponibilizado nos processos de formação inicial e continuado, que tem permitido ao sujeito masculino acessar e ajustar -se à educação como campo de trabalho. O recorte a seguir confirma tal consideração.

Referente a questão do gênero e o preconceito, na escola onde estou nunca fui cobrado desta maneira. Comigo nunca percebi isto, acho que pelos posicionamentos claros e objetivos que defendo com relação à política, a gênero e de estar aberto a estas discussões. Mas quanto a 
Volume, 13, n. 1, ano 2017

essa questão de paternalismo, eu não me vejo e não me sinto confortável. Sobre o preconceito, no meu posicionamento prefiro agir e estar aberto a conversar sobre qualquer assunto com pais ou alunos como faço. Mas, particularmente percebo que o homem se incomoda com estes assuntos e se sentem ameaçados. No geral nem todos estão abertos a estas discussões e isto nem sempre é visto como interessante por determinados colegas professores (Sujeito 2).

Consideramos que não há como negar que as experiências de masculinidade subalternas, conforme o relato de Sujeito 2, também são carregadas de contradições e ocupam uma posição paradoxal. No início do relato, Sujeito2 afirma que, na escola em que trabalha, a "questão de gênero o preconceito", nunca foi cobrada dele. No entanto, ele precisa se resguardar nos "posicionamentos claros e objetivos" que defende, mesmo diante do pouco conforto em abordar questões relacionadas ao paternalismo.

O sujeito vai além no desenho de posição de sujeito paradoxal, pois reconhece que os assuntos, quando abordados, incomodam e fazem os homens se sentirem ameaçados. Por fim, reconhece que "no geral nem todos estão abertos a estas discussões e isto nem sempre é visto como interessante por determinados colegas professores". Ora, todos esses argumentos apresentados vão de encontro à premissa inicial do docente de quem nunca havia sido cobrada uma posição sobre a questão de gênero e do preconceito. O que seria de sua posição e de sua narrativa se o professor não operasse, belicamente, seus posicionamentos claros e objetivos e se não percebesse a ameaça diante da abordagem desses assuntos?

Dessa maneira, conforme nossa análise, a perspectiva de uma masculinidade hegemônica como um sujeito unitário é frágil, pois, de acordo com nossas incursões analíticas, os discursos dos docentes revelam-nos um sujeito multifacetado, paradoxal e dividido. Assim, mesmo que persistam reivindicações sobre a maneira correta de como os homens devem pensar e viver, não importando a diversidade empírica das masculinidades, o pensar de como o tornar-se professor necessita de habilidade e tais marcas subjetivas não relacionam-se com a masculinidade hegemônica, ou mesmo com a conduta e o jeito de pensar e viver de homem masculino hegemônico. São, portanto, profundamente marcadas por experiências no plural!

\section{Considerações finais}




\section{ITMERPAPUS \\ REFLECTIONIS}

Volume, 13, n. 1, ano 2017

Iniciamos essas breves considerações reconhecendo que o sujeito professor pode estar se utilizando da masculinidade subalternizada, em diálogo associativo com as características reconhecidas do campo feminino em diferentes situações no convívio com seus alunos, as quais são reconhecidas como valor para a docência bem-sucedida. Consideremos que as relações entre professores, professoras, alunos, alunas e sentimentos de afeto são algumas das características que não condizem com a ser masculino hegemônico. Apesar do consenso cultural, a centralidade discursiva, a institucionalização e a marginalização ou a deslegitimação de alternativas são características amplamente reconhecidas e predominantemente estudadas no campo das masculinidades hegemônicas.

Consideremos, nisso, que a masculinidade hegemônica não necessita ser o padrão comum na vida diária de meninos e homens no cotidiano, ou mesmo na família e na escola. Longe disso, as masculinidades emergem em meio a experiências subalternas, dissonantes das hegemônicas e paradoxais. Nesse sentido, observamos que tais mudanças de paradigma têm sido exigidas na sociedade de nosso tempo visando ajustes sociais e familiares, suscitando novas estratégias nas relações de poder e resultado em redefinições da masculinidade socialmente admirada.

É dessa forma que a educação também pode estar sendo adequada a essas outras masculinidades. Isso porque o sujeito professor se distancia da masculinidade hegemônica e se utiliza da subalternidade masculina para o tornar-se professor, ajustandose melhor ao campo das habilidades e competências dele exigidas, mesmo que esteja fora do padrão esperado em outros espaços dessa mesma sociedade. Ali esse sujeito professor reinventa sua posição de sujeito e re-aloca-se nas relações de poder que emergem no campo social da escola.

Conclusivamente, embora a escola ainda persista como instituição coercitiva, em que as leis de manutenção de valores são incrustadas na pele, músculos, vísceras e ossos de todos que ali estão, disseminando-se também aos que chegam, precisamos despertar para a percepção de que o corpo ignorado, paralisado e dominado é domesticação. Ainda, consideremos que as formas de coerção, mesmo que sutis, persistem na escola e que a ausência das palmatórias, as salas de castigo ou as cópias intermináveis encontraram em outros dispositivos a manutenção do controle e do adestramento, inclusive no campo do gênero e também da sexualidade. 


\section{ITHERARHS \\ REFLECTIONIS}

Volume, 13, n. 1, ano 2017
DA GRADUAÇÃO/PÓS-GRADUAÇÃO EM EDUCAÇÃO

ISSN. 1807-9342

Vale considerar que o controle está em cada corpo e identidade na escola, como porta-voz inconsciente dos dogmas de intolerância e exclusão da diferença. Portanto, acreditamos que uma subjetividade, quer masculina ou feminina, fundada na multiplicidade e na convivência pacífica com a diversidade é o que estabelece parâmetros bem distintos daquilo que foi forjando em nós e exigido de nossas condutas desde a infância. Teriam sido marcas em que a humilhação e a exclusão serviram de modeladores de nossas subjetividades.

Acreditamos, portanto, que subjetividades masculinas podem fazer diferenças na escola do nosso tempo por serem forjadas sempre na condição de subalterna. Apostamos que elas podem estar fazendo diferença no processo educativo usando-se de rotas de fuga para tornarem-se corpos e mentes a viverem como obra de arte. Ou seja, a cada dia uma nova aventura, novas identidades e obra, criação, desafio, superação e transposição do que lhes são impostos como regra e padrão. Por isso, são re-criadas e, delas, novos sentidos são dados aos corpos, mesmo os anteriormente vistos como inadequados.

\section{Referências}

BADINTER, E. XY: Sobre a identidade masculina. Rio de Janeiro: Nova Fronteira. 1999.

BUTTLER, J. Problemas de gênero: Feminismo e subversão da identidade. Rio de Janeiro: Civilização Brasileira. 2003.

COONNELL, R. W. Políticas da masculinidade. Educação \& Realidade, V.20, n. 2. 1995.

; MESSERSCHMIDT, J. W. Masculinidade hegemônica: repensando o conceito. Estudos Feministas, Florianópolis, 21(1), Janeiro-Abril/2013.

FERNANDES, C. A. Discurso e sujeito em Michel Foucault. São Paulo: Intermeios, 2012.

FISCHER, R. M. B. Foucault e a análise de discurso em educação. Cadernos de pesquisa. Porto Alegre: n.114. 2001.

FOUCAULT, M. Ditos e Escritos volume IV. Rio de Janeiro: Forense Universitária. 2004.

2007.

História da sexualidade volume I: a vontade de saber. Rio de Janeiro: Graal. A arqueologia do saber. Rio de Janeiro: Forense Universitária, 2008. 
Volume, 13, n. 1, ano 2017 A hermenêutica do sujeito. São Paulo: Martins e fontes. 2011a

Foucault. M. A ordem do discurso. São Paulo: Loyola, 2011b

GONDRA, J. G. Educação no Brasil: História, cultura e política. Bragança Paulista: EDUSF. 2008.

GONZALEZ REY, F. L. Pesquisa qualitativa e subjetividade: os processos de construção da informação. São Paulo: Thomson Pioneira, 2005.

HERCULANO. M. C. Afetividade na Relação Professor-Aluno: Significados sob o olhar do professor do ensino médio. 2011. Dissertação Mestrado. - Universidade Estadual do Ceará 2011.

LOURO, G. L. O corpo educado: Pedagogias da sexualidade. Belo Horizonte: Autentica. 1999.

Um corpo estranho: Ensaios sobre sexualidade e teoria queer. Belo Horizonte: Autêntica. 2004.

Mulheres nas salas de aulas. In Priore, M. (org.) História das mulheres no Brasil. São Paulo: Contexto, 1997

Vozes. 2008.

. Gênero, sexualidade e educação: Uma perspectiva pós-estruturalista. Petrópolis:

Foucault, M. e os estudos queer. In: RAGO, Margareth. VEIGA-NETO, Alfredo. Para uma vida não-fascista. Belo Horizonte: Autêntica. 2009.

MANN, C.; STEWART, F. Internet Communication and Qualitative Research: a handbook for researching online. London: SAGE Publications, 2000.

MARCUSCHI, L. A. Gêneros textuais emergentes no contexto da tecnologia digital. In: MARCUSCHI, L. A. XAVIER, A. C.s (Orgs.). Hipertexto e Gêneros Digitais. Rio de Janeiro: Ed. Lucerna, 2004.

MISKOLCI, R. A teoria queer e a sociologia: O desafio de uma analítica da normalização. Sociologias. Porto Alegre: ano 11. v. 1. n. 29. 2009

Novas conexões: Notas teórico-metodológicas para pesquisas sobre o uso de mídias digitais. Cronos: R. Pós-Grad. Ci. Soc. UFRN, v. 12. n.2. 2011

MORAES, M. C.; TORRE, S. de la. Sentipensar: fundamentos e estratégias para reencantar a educação. Rio de Janeiro: Vozes, 2004.

NÓVOA, A. Os professores e as histórias de vida. In: Vidas de professores, Porto: Porto Editora, 2000, p. 11-30. 
Volume, 13, n. 1, ano 2017

PAIS, J. M. Ganchos, tachos e biscates: jovens, trabalho e futuro. Porto: Ambar, 2001.

PERRENOUD, P. Práticas pedagógicas profissão docente e formação: perspectivas sociológicas. Lisboa: Dom Quixote, 1993.

PERRENOUD, P. 10 Novas Competências para Ensinar. Porto Alegre, Artmed Editora, 2000 .

Práticas pedagógicas profissão docente e formação: perspectivas sociológicas. Lisboa: Dom Quixote, 1993. PIMENTA, S. G. (Org.). Saberes pedagógicos e atividade docente. São Paulo: Cortes, 1999.

PIMENTA, S. G. (Org.). Saberes pedagógicos e atividade docente. São Paulo: Cortes, 1999

SANTOS, W. B.; DINIS, N. F. Adolescência heteronormativa masculina: entre a construção "obrigatória" e desconstrução necessária. OPSIS, Catalão, v. 13, n. 2, p.129$149,2013$.

A pesquisa em educação, as tecnologias digitais e metodologias: reflexões sobre como acessar discursos de estudantes adolescentes. in Leão, A. M. C. Muzzeti, R. L. (org) Perspectivas, práticas e reflexões educacionais. São Paulo. Ed. Cultura Acadêmica. 2015

SANTOS, W. B. Adolescência heteronormativa masculina: entre a construção "obrigatória” e desconstrução necessária. São Paulo, Ed. Intermeios. 2016

SCOTT, J. W. Gênero: uma categoria útil de análise histórica. Educação \& Realidade. Porto Alegre: v. 20. n. 2. 1995.

Prefácio. A gender and politics of history. Cadernos Pagu, v.3, p.12, 1994.

SILVA, T. T. da. Documentos de Identidade: uma introdução às teorias do currículo. Belo Horizonte: Autêntica, 2005.

SHULMAN, L. "Those Who Understand: Knowledge Growth in teaching". In: Educational Researcher, Washington, AERA, 1986, p. 4-14.

TARDIF, M. Saberes docentes e formação profissional. Petrópolis, Editora Vozes, 2002.

WEEKS, J. Sexuality. New York: Routdledge. 1986.

WARNER, M. Fear of a queer planet: Queer Politics and Social Theory. London: University of Minnesota Press. 1991. 